\title{
Common eye infections
}

\section{SUMMARY}

Not all red eyes are due to infections. Not all eye infections respond to antibiotic eye drops.

Conjunctivitis is the most common eye infection. Most cases are viral and do not require antibiotic eye drops.

Infectious keratitis is a cause of blindness. It is an emergency that requires specialist treatment.

Infectious endophthalmitis is an emergency that has become more frequent with the use of intravitreal injections. Intravitreal antibiotics are needed to try and prevent visual loss.

\section{Introduction}

Eye infections are a common presenting problem in primary care. 'Red eye', 'conjunctivitis' and 'corneal ulcer/keratitis' were among the top five problems most commonly referred to two ophthalmology departments in Brisbane.

To ensure a good visual outcome for the patient, the practitioner should make a prompt diagnosis and start appropriate treatment. Conjunctivitis typically does not threaten vision, but infections of the cornea or inside the eye are serious threats and require immediate referral to an ophthalmologist.

\section{Infectious conjunctivitis}

Conjunctivitis is a common condition that causes dilation of the conjunctival blood vessels and results in inflammation. Figure 1 is an algorithmic approach to diagnosing and treating conjunctivitis, based on signs and symptoms. ${ }^{2}$

Both viral and bacterial conjunctivitis (Fig. 2) present with a red eye and are highly contagious. Assessment should include checking visual acuity and examination with a torch or slit lamp. Fluorescein drops should be instilled in the conjunctival sac and the eye viewed with the cobalt blue light of the slit lamp or fundoscope, to rule out any signs of corneal ulceration or infection (Fig. 3). A history of cold sores or shingles should be sought and the patient examined for cold sores or a vesicular rash in case the infection is due to herpes simplex or zoster virus.

\section{Viral conjunctivitis}

Viral conjunctivitis is the most common cause of infectious conjunctivitis. This infection is more common in adults than in children. Around $65-90 \%$ of cases are caused by adenovirus. Occasionally, herpes simplex or zoster virus is responsible.

Patients can generally be advised that viral conjunctivitis is self-limiting and, as there are no specific treatments, for comfort they can use cold compresses, artificial tears or topical antihistamines..$^{2,3}$ Antibiotics are not needed, are costly and may increase antibiotic resistance. If there is evidence of herpes simplex or zoster virus then antivirals should be prescribed, such as aciclovir ointment or ganciclovir gel.

When viral conjunctivitis is severe or the patient experiences symptoms after its resolution, the patient should be referred to an ophthalmologist. This is to consider topical steroids and to exclude an immune 'post-viral' keratitis.

\section{Bacterial conjunctivitis}

Bacterial conjunctivitis, although a less frequent cause of conjunctivitis, is more common in children. The most common bacteria are Haemophilus influenza, Streptococcus pneumoniae and Staphylococcus aureus. Compared to placebo, the use of antibiotic eye drops is associated with improved rates of clinical and microbiological remission. ${ }^{4} \mathrm{~A}$ broad-spectrum topical antibiotic is recommended. The practitioner can select the most convenient or least expensive option, as there is no clinical evidence suggesting the superiority of any particular antibiotic. ${ }^{3,4}$

The initial treatment recommended by Therapeutic Guidelines: Antibiotic ${ }^{5}$ is:

- chloramphenicol $0.5 \%$ eye drops, one to two drops every two hours for the first 24 hours, decreasing to six-hourly until the discharge resolves, for up to seven days

- framycetin sulfate $0.5 \%$ eye drops, 1-2 drops every 1-2 hours for the first 24 hours, decreasing to eighthourly until discharge resolves for up to seven days.

Chloramphenicol $1 \%$ eye ointment may be used at bedtime. Gentamicin, tobramycin and quinolone eye drops are not recommended for empiric treatment. If the condition does not improve within five days, the patient should be immediately referred to an ophthalmologist.

\section{Stephanie Watson \\ Professor}

Maria Cabrera-Aguas

Clinical research officer

\section{Pauline Khoo}

Clinical research officer

Save Sight Institute

University of Sydney

\section{Keywords}

conjunctivitis,

endophthalmitis, eye

infection, keratitis

Aust Prescr 2018;41:67-72

https://doi.org/10.18773/ austprescr.2018.016 


\section{Fig. 1 Suggested procedure for clinical approach to suspected acute conjunctivitis}

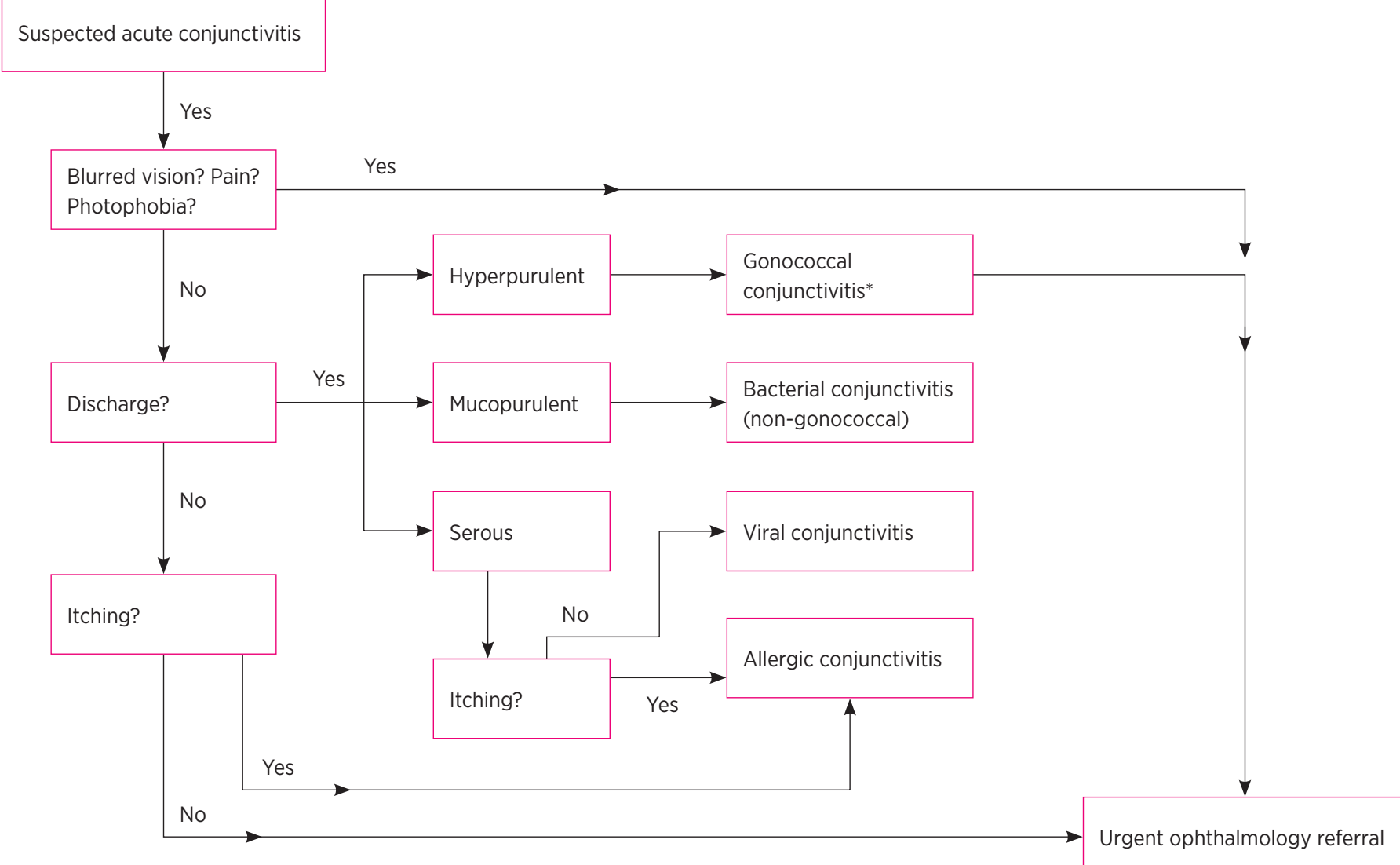

* Gonococcal conjunctivitis is mainly seen in neonates

\section{Fig. 2 Conjunctivitis}

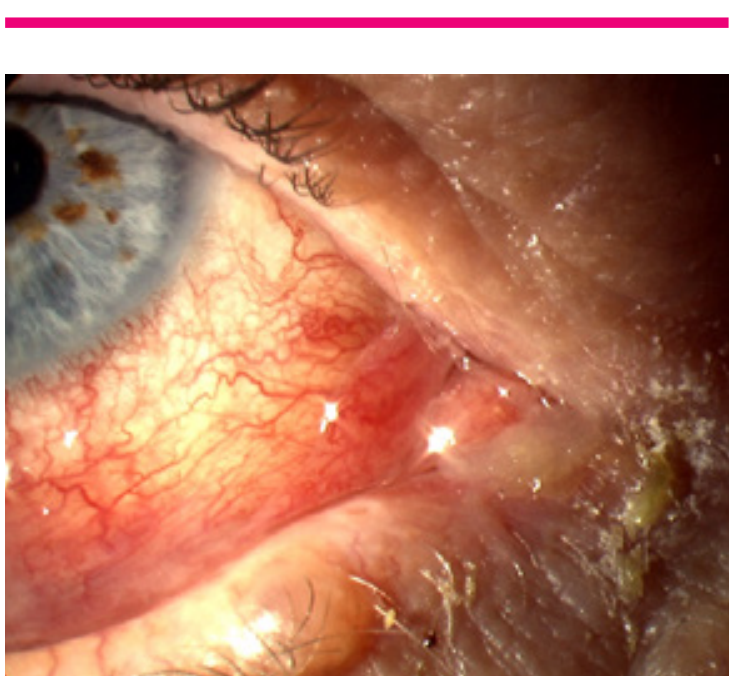

Note discharge at medial canthus.
Fig. 3 Epithelial defect in a corneal graft viewed with fluorescein drops and cobalt blue light

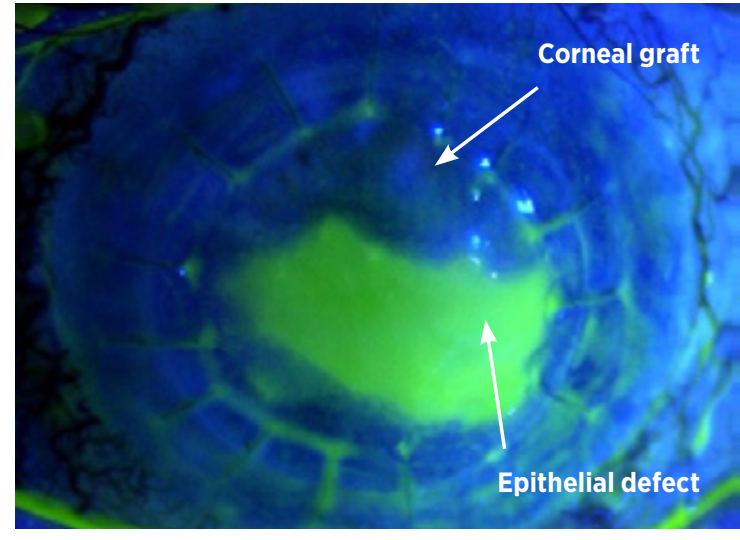

The epithelial defect is stained green. 


\section{Gonococcal conjunctivitis}

Conjunctivitis caused by Neisseria gonorrhoeae is uncommon but should be considered in neonates and sexually active young adults. If suspected, the practitioner should take conjunctival swabs for Gram staining and special culture for Neisseria species. ${ }^{6}$ Patients should be referred immediately to an ophthalmologist. Antibiotic therapy is the recommended treatment and ceftriaxone is the drug of choice. ${ }^{3}$ Additionally, patients should lavage the infected eye with saline and add therapy to cover chlamydia. ${ }^{2}$

\section{Chlamydial conjunctivitis}

Most cases of chlamydial conjunctivitis are unilateral and have concurrent genital infection. Symptoms usually include conjunctival hyperemia, mucopurulent discharge and lymphoid follicle formation. ${ }^{6}$ Patients with symptoms should be referred immediately to an ophthalmologist. Oral antibiotics such as azithromycin or doxycycline are effective treatments.?

\section{Infectious keratitis}

Infection of the cornea (microbial keratitis) is an ophthalmic emergency requiring immediate attention as it can progress rapidly. It is a significant cause of corneal blindness ${ }^{8}$ and is one of the most common causes of visual impairment in working age adults. ${ }^{9}$ In the USA, about 30000 cases of microbial keratitis are reported annually. ${ }^{10}$
If infectious keratitis is suspected, the practitioner should take a history to look for risk factors such as contact lenses, corneal abrasions, physical and chemical trauma, refractive surgery, diabetes, immunosuppressive diseases and topical steroids. ${ }^{10,11}$ The type of infecting organism varies according to the climate and geographical region and the patient's risk factors.

\section{Bacterial keratitis}

Bacterial infection is the most common cause of infectious keratitis. Common causal bacteria include $S$. aureus, coagulase-negative staphylococci, S. pneumoniae and Pseudomonas aeruginosa. ${ }^{10,11}$ $P$. aeruginosa is the most common microorganism implicated in bacterial keratitis among contact lens wearers. Less commonly, fungi or acanthamoeba can be responsible. ${ }^{12}$ Fungi should be suspected when there is trauma particularly with vegetative matter and is more common in rural environments. Suspect acanthamoeba if a patient has been swimming or in a spa while wearing contact lenses. Specific antifungal or anti-acanthamoebal therapy is needed and treatment may take some months. ${ }^{13-15}$

The signs and symptoms of bacterial keratitis are shown in the Table and Fig. 4. ${ }^{16}$ Patients with pain, photophobia, blurred vision, corneal opacity or hypopyon (pus inside eye), or contact lens wearers with red eye or increasing pain, should be referred promptly to an ophthalmologist for a slit lamp

\section{Table Clinical features of keratitis and endophthalmitis}

\begin{tabular}{|c|c|c|c|}
\hline Condition & Common symptoms & Common signs & History \\
\hline Bacterial keratitis & $\begin{array}{l}\text { Pain } \\
\text { Photophobia } \\
\text { Tearing } \\
\text { Decreased or blurred vision }\end{array}$ & $\begin{array}{l}\text { Redness } \\
\text { Discharge } \\
\text { Corneal ulcer } \\
\text { Corneal infiltrates } \\
\text { Hypopyon }\end{array}$ & $\begin{array}{l}\text { Contact lens wear } \\
\text { Trauma }\end{array}$ \\
\hline Herpes simplex virus keratitis & $\begin{array}{l}\text { Pain } \\
\text { Decreased or blurred vision } \\
\text { Tearing } \\
\text { Itching } \\
\text { Photophobia }\end{array}$ & $\begin{array}{l}\text { Redness } \\
\text { Discharge } \\
\text { Epithelial: } \\
\text { - Dendritic ulcer } \\
\text { Stromal: } \\
\text { - Stromal haze/opacity } \\
\text { with or without ulceration } \\
\text { - Scarring } \\
\text { - Vascularisation } \\
\text { Endothelial: } \\
\text { - Stromal oedema } \\
\text { - Keratitic precipitates }\end{array}$ & $\begin{array}{l}\text { Labial cold sores } \\
\text { Prior keratitis }\end{array}$ \\
\hline Endophthalmitis & $\begin{array}{l}\text { Pain } \\
\text { Decreased vision }\end{array}$ & $\begin{array}{l}\text { Redness } \\
\text { Hypopyon }\end{array}$ & $\begin{array}{l}\text { Recent ocular surgery } \\
\text { Intravitreal injections } \\
\text { Trauma } \\
\text { Intravenous drug use }\end{array}$ \\
\hline
\end{tabular}


examination and corneal scraping. These scrapings are sent for Gram stain and culture to identify the organism. To begin, treatment has to be empiric because the results can take over 48 hours, and the condition can progress rapidly with loss of vision or even the eye if treatment is not started.

Topical antibiotics are the mainstay of treatment and options include monotherapy with fluoroquinolones (ciprofloxacin $0.3 \%$ or ofloxacin $0.3 \% 1-2$ drops hourly for 48 hours, then every 4 hours until healed) or fortified aminoglycoside/cephalosporin combinations (fortified cefalotin 5\% plus gentamicin 0.9\% 1-2 drops hourly for 48 hours, then reduce frequency according to treatment response). ${ }^{5}$ These regimens have similar effectiveness but fluoroquinolones reduce the risk of chemical conjunctivitis and ocular discomfort. Compared to ofloxacin, ciprofloxacin increases the risk of white corneal precipitates. ${ }^{17}$ Occasionally, corneal grafting may be needed to eradicate the organism or repair damage.

Chloramphenicol is the most common first-line antibiotic prescribed for red eye. It is a bacteriostatic broad-spectrum antibiotic but lacks activity against $P$. aeruginosa. ${ }^{18}$ Primary healthcare providers should not prescribe chloramphenicol when microbial keratitis is suspected as this delays appropriate treatment, with the risk of the patient losing vision or the eye..$^{18,19}$

\section{Herpes simplex keratitis}

Keratitis caused by herpes simplex virus is an important cause of infectious blindness in developed countries. The global incidence of herpes simplex keratitis was calculated at approximately 1.5 million with 40000 new cases of severe monocular visual impairment or blindness per year. ${ }^{20}$ Herpes simplex keratitis can be

\section{Fig. 4 Bacterial keratitis}

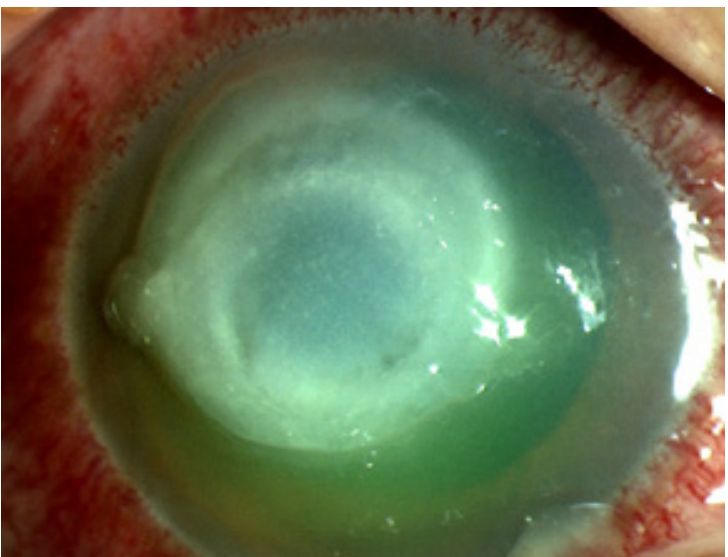

The central cornea has a white opacity known as an 'inflitrate' with an epithelial defect and conjunctival injection. classified as epithelial, stromal, endothelial or mixed, depending on which layer of the cornea is involved (Fig. 5). It may also be considered as primary or recurrent depending on whether it is the patient's first episode. If suspected, the practitioner should ask about a history of cold sores or previous viral keratitis as this can be the first clue to the diagnosis. The clinical features of herpes simplex virus keratitis (Table) can be identified on slit lamp examination. ${ }^{21,22}$ Epithelial herpes simplex keratitis typically manifests as a dendritic ulcer. To visualise the ulcer, fluorescein staining and a cobalt blue light are needed (Fig. 5). ${ }^{21}$ The treatment is aciclovir ointment five times daily for 14 days. ${ }^{23-25}$

Stromal herpes simplex keratitis presents with haze or opacity of the stroma, with or without ulceration, scarring or vascularisation. Endothelial keratitis is characterised by keratitic precipitates on the endothelium and corneal oedema. ${ }^{23}$ Management of stromal and endothelial keratitis involves referral to an ophthalmologist for oral antivirals (aciclovir or valaciclovir), topical steroids ${ }^{25}$ and follow-up until the episode has resolved.

\section{Infectious endophthalmitis}

Endophthalmitis is an inflammation inside the eye that can be caused by infection with microbes, including bacteria or fungi (Fig. 6). The Table lists the clinical features. Endophthalmitis is an ocular emergency, requiring urgent referral to an ophthalmologist to prevent permanent loss of vision. It is a rare condition and its incidence depends on the cause. Risk factors for endophthalmitis include cataract surgery, intravitreal injections (for age-related macular

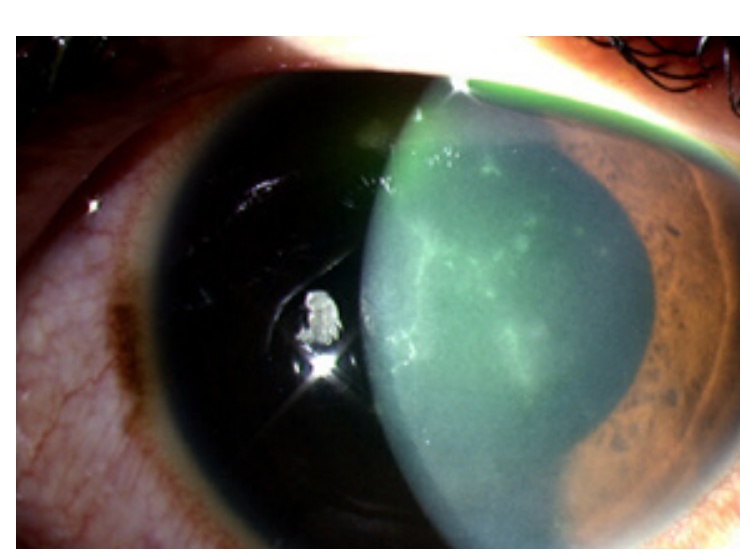

This photograph illustrates an epithelial dendrite from herpes simplex keratitis seen with fluorescein staining and a cobalt blue light. 
degeneration), trauma, filtering bleb (for glaucoma), corneal infection, bacteraemia or fungemia.

Endophthalmitis due to systemic infection may be associated with intravenous drug use.

Worldwide, cataract surgery is the most common cause of endophthalmitis, occurring in around 1 in 1000 cases. ${ }^{26}$ It typically presents within seven days of the surgery and is most often caused by bacteria.

The incidence of endophthalmitis following intravitreal injections is increasing along with the widespread use of intravitreal antivascular endothelial growth factors for managing neovascular age-related macular degeneration and diabetic retinopathy. The risk of endophthalmitis is $0.05 \%$ per injection and, with injections often given monthly, the risk is cumulative. Typically, patients present within five days of the injection with decreased vision and pain. The most common microorganisms involved are coagulasenegative staphylococci, S. aureus, streptococci and Gram-negative bacilli. A minor procedure is needed to obtain samples of vitreous and aqueous humour to isolate the organism.

Urgent treatment is needed with intravitreal antibiotics such as ceftazidime or vancomycin injected by an ophthalmologist. In some cases vitrectomy may be beneficial to avoid loss of vision. ${ }^{5,27}$ If there is a delay in administering intravitreal treatment, give single doses of:

- oral ciprofloxacin $750 \mathrm{mg}$ (child: $20 \mathrm{mg} / \mathrm{kg}$ up to $750 \mathrm{mg}$ ) plus intravenous vancomycin (adult and child $15 \mathrm{mg} / \mathrm{kg}$ )

- gentamicin (adult and child $5 \mathrm{mg} / \mathrm{kg}$ ) intravenous plus intravenous cefazolin $2 \mathrm{~g}$ (child: $50 \mathrm{mg} / \mathrm{kg}$ up to $2 \mathrm{~g})^{5}$

\section{Fig. 6 Endophthalmitis}

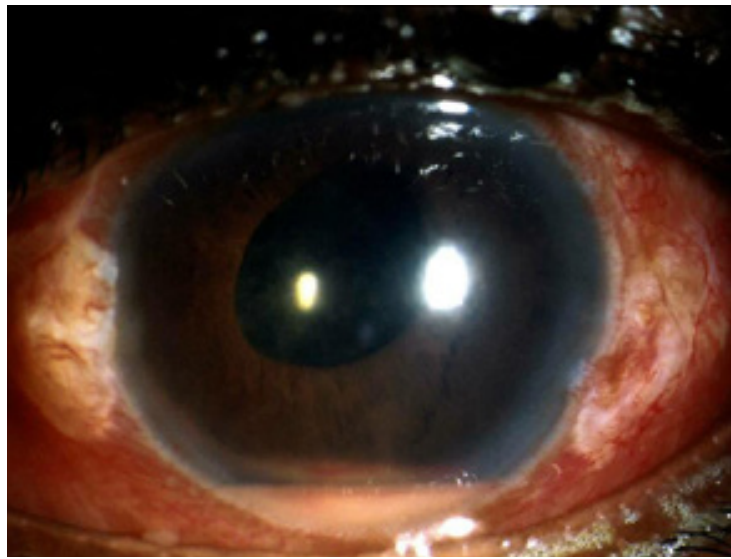

In this photograph of a patient's eye with endophthalmitis a pus level inside the front of the eye, known as a hypopyon, can be seen.

\section{Adverse effects of topical antibiotics}

Bacterial infections are typically treated with antibiotic drops which may cause systemic adverse effects. The volume of commercial dispensers (25-50 microlitres) exceeds the capacity of the conjunctival sac (10 microlitres), therefore a large volume of the liquid drains out of the eye. This liquid may be systemically absorbed through different pathways including conjunctiva, nose, lacrimal drainage, pharynx, gastrointestinal tract, aqueous humour, lids, cheeks and inner ocular tissues. However, the risk of systemic absorption is low since ocular drug bioavailability is $5-10 \%$ and the corneal epithelium and conjunctival epithelium act as natural barriers limiting absorption. ${ }^{28}$ Some adverse effects include skin irritation, itching or rash with sulfonamide, sulfacetamide and neomycin. ${ }^{28}$ Fluoroquinolones can cause local irritation, stinging, chemosis, conjunctival hyperaemia, corneal precipitations and alteration of taste. ${ }^{29}$

A minimal dose and concentration of the antibiotic must be used in pregnancy to limit systemic absorption. Patients must be advised of punctal occlusion, nasolacrimal pressure and wiping away extra liquid to prevent systemic absorption. ${ }^{30}$ Practitioners should refer to the $A B C D$ pregnancy category before prescribing antibiotics to pregnant women. Antibiotics and antivirals such as chloramphenicol, tobramycin, fluoroquinolones and topical aciclovir are considered safe to use during pregnancy. ${ }^{31}$

\section{Conclusion}

Patients with eye infections typically present with pain, blurred vision and a red eye. Conjunctivitis is the most common eye infection to present to primary healthcare providers and rarely threatens vision. Corneal infection (keratitis) and endophthalmitis are less common but pose a serious risk to vision. If the patient has a history of blurred vision, pain, photophobia, corneal opacity or hypopyon, specialist assessment is urgently needed.

Primary healthcare providers should avoid prescribing topical antibiotics for an eye infection unless the patient has bacterial conjunctivitis. Viral conjunctivitis is common and self-limiting. Urgent referral to an ophthalmologist for microbiological samples and treatment is needed for infectious keratitis and endophthalmitis. $<$

The authors have received financial support from the Sydney Eye Hospital Foundation.
SELF-TEST QUESTIONS

True or false?

1. Chloramphenicol eye drops should not be used to treat bacterial keratitis.

2. In adults, most infectious conjunctivitis is caused by a virus.

Answers on page 95 


\section{REFERENCES}

1. Statham MO, Sharma A, Pane AR. Misdiagnosis of acute eye diseases by primary health care providers: incidence and implications. Med J Aust 2008;189:402-4.

2. Azari AA, Barney NP. Conjunctivitis: a systematic review of diagnosis and treatment. JAMA 2013:310:1721-9. https://doi.org/10.1001/jama.2013.280318

3. American Academy of Ophthalmology Cornea/External Disease Panel. Preferred Practice Pattern ${ }^{\oplus}$ Guidelines Conjunctivitis. San Franciso (CA): American Academy of Ophthalmology; 2013. https://www.aao.org/preferredpractice-pattern/conjunctivitis-ppp--2013 [cited 2018 May 1]

4. Sheikh A, Hurwitz B. Antibiotics versus placebo for acute bacterial conjunctivitis. Cochrane Database Syst Rev 2006;(2):CD001211. https://doi.org/10.1002/ 14651858.CD001211.pub2

5. Therapeutic Guidelines. Antibiotic. Version 15. Melbourne: Therapeutic Guidelines Limited; 2014

6. Morrow GL, Abbott RL. Conjunctivitis. Am Fam Physician 1998;57:735-46.

7. Katusic D, Petricek I, Mandic Z, Petric I, Salopek-Rabatic J, Kruzic V, et al. Azithromycin vs doxycycline in the treatment of inclusion conjunctivitis. Am J Ophthalmol 2003;135:447-51. https://doi.org/10.1016/S0002-9394(02)02094-9

8. Allan BD, Dart JK. Strategies for the management of microbial keratitis. Br J Ophthalmol 1995;79:777-86. https://doi.org/10.1136/bjo.79.8.777

9. Whitcher JP, Srinivasan M, Upadhyay MP. Corneal blindness: a global perspective. Bull World Health Organ 2001;79:214-21.

10. Sharma A, Taniguchi J. Review: Emerging strategies for antimicrobial drug delivery to the ocular surface: Implications for infectious keratitis. Ocul Surf 2017;15:670-9. https://doi.org/10.1016/j.jtos.2017.06.001

11. Green M, Apel A, Stapleton F. Risk factors and causative organisms in microbial keratitis. Cornea 2008;27:22-7. https://doi.org/10.1097/ICO.0b013e318156caf2

12. Stapleton F, Dart JK, Seal DV, Matheson M. Epidemiology of Pseudomonas aeruginosa keratitis in contact lens wearers. Epidemiol Infect 1995;114:395-402. https://doi.org/10.1017/ S0950268800052109

13. Maycock NJ, Jayaswal R. Update on acanthamoeba keratitis: diagnosis, treatment, and outcomes. Cornea 2016:35:713-20. https://doi.org/10.1097/ICO.0000000000000804

14. Thomas PA, Kaliamurthy J. Mycotic keratitis: epidemiology, diagnosis and management. Clin Microbiol Infect 2013;19:210-20. https://doi.org/10.1111/1469-0691.12126

15. Ong HS, Fung SS, Macleod D, Dart JK, Tuft SJ, Burton MJ. Altered patterns of fungal keratitis at a London ophthalmic referral hospital: an eight-year retrospective observational study. Am J Ophthalmol 2016;168:227-36. https://doi.org/ 10.1016/j.ajo.2016.05.021

16. Thomas PA, Geraldine P. Infectious keratitis. Curr Opin Infect Dis 2007;20:129-41. https://doi.org/10.1097/ QCO.0b013e328017f878

17. McDonald EM, Ram FS, Patel DV, McGhee CN. Topical antibiotics for the management of bacterial keratitis: an evidence-based review of high quality randomised controlled trials. Br J Ophthalmol 2014;98:1470-7. https://doi.org/10.1136/bjophthalmol-2013-304660
18. Robaei D, Naunton M, Watson S. Seeing red: over-thecounter chloramphenicol. Clin Experiment Ophthalmol 2015;43:99-100. https://doi.org/10.1111/ceo.12497

19. McDerby N, Watson SL, Robaei D, Naunton M. Inappropriate use of topical chloramphenicol results in vision loss. Clin Experiment Ophthalmol 2015;43:192-3. https://doi.org/ 10.1111/ceo.12465

20. Faroog AV, Shukla D. Herpes simplex epithelial and stromal keratitis: an epidemiologic update. Surv Ophthalmol 2012;57:448-62. https://doi.org/10.1016/ survophthal.2012.01.005

21. Azher TN, Yin XT, Tajfirouz D, Huang AJ, Stuart PM. Herpes simplex keratitis: challenges in diagnosis and clinical management. Clin Ophthalmol 2017;11:185-91. https://doi.org/10.2147/OPTH.S80475

22. Rowe AM, St Leger AJ, Jeon S, Dhaliwal DK, Knickelbein JE, Hendricks RL. Herpes keratitis. Prog Retin Eye Res 013;32:88-101. https://doi.org/10.1016/j.preteyeres.2012.08.002

23. Guess S, Stone DU, Chodosh J. Evidence-based treatment of herpes simplex virus keratitis: a systematic review. Ocul Surf 2007;5:240-50. https://doi.org/10.1016/ S1542-0124(12)70614-6

24. Wilhemus KR. Antiviral treatment and other theraputic interventions for herpes simplex virus epithelial keratitis. Cochrane Database Syst Rev 2010;CD002898. https://doi.org/10.1002/14651858.CD002898.pub4

25. White ML, Chodosh J. Herpes simplex virus keratitis: a treatment guideline. 2014. www.aao.org/clinicalstatement/herpes-simplex-virus-keratitis-treatmentguideline [cited 2018 May 1]

26. Keay L, Gower EW, Cassard SD, Tielsch JM, Schein OD. Postcataract surgery endophthalmitis in the United States: analysis of the complete 2003 to 2004 Medicare database of cataract surgeries. Ophthalmology 2012;119:914-22. https://doi.org/10.1016/j.ophtha.2011.11.023

27. Durand ML. Bacterial and fungal endophthalmitis. Clin Microbiol Rev 2017;30:597-613. https://doi.org/10.1128/ CMR.00113-16

28. Farkouh A, Frigo P, Czejka M. Systemic side effects of eye drops: a pharmacokinetic perspective. Clin Ophthalmol 2016;10:2433-41. https://doi.org/10.2147/OPTH.S118409

29. Thompson AM. Ocular toxicity of fluoroquinolones. Clin Experiment Ophthalmol 2007;35:566-77. https://doi.org/10.1111/j.1442-9071.2007.01552.x

30. Chawla S, Chaudhary T, Aggarwal S, Maiti GD, Jaiswal K, Yadav J. Ophthalmic considerations in pregnancy. Med J Armed Forces India 2013;69:278-84. https://doi.org/ 10.1016/j.mjafi.2013.03.006

31. Chung CY, Kwok AK, Chung KL. Use of ophthalmic medications during pregnancy. Hong Kong Med J 2004;10:191-5. 